\title{
Launch of the HKMJ Expert Advisory Panel on Social Media: enhancing reach, timeliness, and efficient sharing of medical literature
}

\author{
Martin CS Wong ${ }^{1,2}$, MD MPH, Jeremy YC Teoh ${ }^{3,4}$ *, MB, ChB, FHKAM (Surgery) \\ Editor-in-Chief, Hong Kong Medical Journal \\ ${ }^{2}$ School of Public Health and Primary Care, Faculty of Medicine, The Chinese University of Hong Kong, Hong Kong \\ ${ }^{3}$ Chair, Expert Advisory Panel on Social Media, Hong Kong Medical Journal \\ ${ }^{4}$ Department of Surgery, Faculty of Medicine, The Chinese University of Hong Kong, Hong Kong
}

* Corresponding author: jeremyteoh@surgery.cuhk.edu.hk

Hong Kong Med J 2020;26:174-5

https://doi.org/10.12809/hkmj205098

Social media refers to internet-based tools that enable individuals and organisations to communicate and share ideas, personal messages, and images. Social media also provides a platform for collaboration among researchers and other like-minded individuals. $^{1}$ These social networking activities have offered our community access to a very rich body of medical knowledge, in order to build both interpersonal and professional relationships. The global utilisation of social media has increased from $7 \%$ in 2005 to $65 \%$ in $2015,{ }^{2}$ and has increasingly played a crucial role for the academic community to promote research, establish academic networks, and interact with the general public online. Many journals have now started to harness the influential capabilities of social media to share their articles to potential readers. ${ }^{3}$ Altmetrics, another metric of evaluating research impact, considers engagement of social media in computing impact. ${ }^{4,5}$

Is there evidence that social media works? In this digital era, the advancement in technology has allowed rapid communications without geographical restrictions. The use of social media and hashtags have been a norm for academics to have rapid exchange of information during medical conferences. It is not uncommon to have a 'viral effect' in the dissemination of medical information, where the degree of interaction and engagement among participants can be very overwhelming. ${ }^{6}$ Hawkins et $\mathrm{al}^{7}$ have analysed the impact of Twitter "tweet chat" sessions by evaluating the Twitter activity metadata tagged with the \#JACR hashtag from tweet chat sessions promoted by the Journal of American College of Radiology. They found that the average monthly journal website visits and page views directly from Twitter increased 321\% and $318 \%$, respectively. In addition, the authors found that organising Twitter microblogging activities around disciplines of general interest to their target audience could potentially increase the reach and number of readers for medical journals. There is also evidence that citations to an article may be heavily reliant on visible exposure of the academic output. ${ }^{8}$ It has been argued that composing a highquality article in journals could only confer $50 \%$ of the chance of being cited, whilst the other half rested on broad promotion and dissemination of the published articles. ${ }^{9-11}$ The objectives of employing social media for medical journals include enhancing their reach, timeliness, and efficiency of sharing medical literature. These objectives are shared by the Hong Kong Medical Journal (HKMJ), as pledged at the Journal's inception in 1995 to provide "a useful source of medical information on advances in medical research and clinical practice"12 in a timely and efficient manner, and reiterated in February $2017 .^{13}$

It is important that articles published in HKMJ reached and benefit as many readers as possible. Among the 10 most frequently cited HKMJ articles in the past years, seven were published in the Review Article or Medical Practice sections ${ }^{14-20}$; these papers likely represent more practice-changing content, and deserve to be disseminated to as wide an audience as possible. In order to expand the audience of HKMJ, from 1 June 2020 onwards, the Journal will formally launch a social media presence, overseen by the "HKMJ Expert Advisory Panel on Social Media". Professor Jeremy Yuen-chun Teoh, an Editor of the HKMJ, has agreed to act as Panel Chair. We are also pleased and grateful that Dr Regina Sit, our Editor, and the three newest members of our Editorial Board, Dr Jason Yam, Dr Sherry Chan, and Dr Jason Cheung have also agreed to join the panel. These three individuals were awardees of the 2019 Best Original Research by Young Fellows, organised by the Hong Kong Academy of Medicine Foundation.

There are at least three social media platforms that we will leverage, including Facebook, Twitter, and LinkedIn, with each bringing different benefits: Facebook is currently the most widely used social media platform in Hong Kong ${ }^{21}$; Twitter allows fast and efficient communication with academics globally $^{22,23}$; and LinkedIn is more widely used internationally for building professional networks of colleagues and collaborators. We believe these 
platforms will allow us to reach our targeted audience in an effective manner. In order to enhance readership, we will also start presenting key results of newly published studies in the form of visual abstracts; this has been shown to be very useful in enhancing engagement with healthcare professionals. ${ }^{24}$ This panel is also charged to ensure maintenance of patient confidentiality, provision of accurate interpretation of research findings, and ethical use of social media based on the guidelines published by professional organisations such as the American Medical Association. ${ }^{25}$ It is also an obligation to safeguard the quality of information being disseminated and to ensure professional and appropriate use of the social media platforms. We hope our readers will appreciate and utilise these initiatives, and share their thoughts and experience with us, by joining us on social media, or emailing the Editorial Office at hkmj@hkmj.org.hk.

\section{References}

1. Ventola CL. Social media and health care professionals: benefits, risks, and best practices. P T 2014;39:491-520.

2. Enago Academy. How social media promotion increase research citation? Available from: https://www.enago. com/academy/how-social-media-promotion-increaseresearch-citation/. Accessed 10 May 2020.

3. Lopez M, Chan TM, Thoma B, Arora VM, Trueger NS. The social media editor at medical journals: responsibilities, goals, barriers, and facilitators. Acad Med 2019;94:701-7.

4. Cann A, Dimitriou K, Hooley T. Social media: a guide for researchers. February 2011. Available from: https:// www.researchgate.net/publication/261990960_Social_ Media_A_Guide_for_Researchers. Accessed 10 May 2020.

5. Harris S. Making research connections with social media: advice for researchers. 25 March 2015. Available from: https://www.authoraid.info/en/resources/details/1240/. Accessed 10 May 2020.

6. Teoh JY, Mackenzie G, Smith M, et al. Understanding the composition of a successful tweet in urology. Eur Urol Focus 2020;6:450-7.

7. Hawkins CM, Hillman BJ, Carlos RC, Rawson JV, Haines $\mathrm{R}$, Duszak R Jr. The impact of social media on readership of a peer-reviewed medical journal. J Am Coll Radiol 2014;11:1038-43.

8. Marashi SA, Hosseini-Nami SM, Alishah K, et al. Impact of Wikipedia on citation trends. EXCLI J 2013;12:15-9.

9. Ebrahim NA. Publication marketing tools "Enhancing Research Visibility and Improving Citations". October 2012. Available from: https://www.researchgate.net/ publication/232045669_Publication_Marketing_Tools_Enhancing_Research_Visibility_and_Improving_
Citations. Accessed 10 May 2020.

10. Bong Y, Ebrahim NA. Increasing visibility and enhancing impact of research. Asia Research News 30 Apr 2017. Available from: https://papers.ssrn.com/sol3/papers. cfm?abstract_id=2959952. Accessed 10 May 2020.

11. Fagbule OF. Use of social media to enhance the impact of published papers. Ann Ib Postgrad Med 2018;16:1-2.

12. Lee JC, Yu YL. Inaugural editorial. Hong Kong Med J 1995;1:4.

13. Wong MC. Exerting an impact on clinical practiceupholding quality, visibility, and timeliness of publications. Hong Kong Med J 2017;23:4-5.

14. Leung AK, Hon KL, Leong KF, Sergi CM. Measles: a disease often forgotten but not gone. Hong Kong Med J 2018;24:512-20.

15. Kan HS, Chan PK, Chiu KY, et al. Non-surgical treatment of knee osteoarthritis. Hong Kong Med J 2019;25:127-33.

16. Hong YL, Yee CH, Tam YH, Wong JH, Lai PT, Ng CF. Management of complications of ketamine abuse: 10 years' experience in Hong Kong. Hong Kong Med J 2018;24:17581.

17. Tsang AC, Yeung RW, Tse MM, Lee R, Lui WM. Emergency thrombectomy for acute ischaemic stroke: current evidence, international guidelines, and local clinical practice. Hong Kong Med J 2018;24:73-80.

18. Wong PC, Chan YC, Law Y, Cheng SW. Percutaneous mechanical thrombectomy in the treatment of acute iliofemoral deep vein thrombosis: a systematic review. Hong Kong Med J 2019;25:48-57.

19. Yee A, Tsui NB, Chang YN, et al. Alzheimer's disease: insights for risk evaluation and prevention in the Chinese population and the need for a comprehensive programme in Hong Kong/China. Hong Kong Med J 2018;24:492-500.

20. Chiu PK, Lee AW, See TY, Chan FH. Outcomes of a pharmacist-led medication review programme for hospitalised elderly patients. Hong Kong Med J 2018;24:98106.

21. Penetration rate of leading social networks in Hong Kong as of 3rd quarter of 2019. Available from: https:// www.statista.com/statistics/412500/hk-social-networkpenetration/. Accessed 10 May 2020.

22. Mohammadi E, Thelwall M, Kwasny M, Holmes KL. Academic information on Twitter: A user survey. PLoS One 2018;13:e0197265.

23. Gudaru K, Blanco LT, Castellani D, et al. Connecting the urological community: The \#UroSoMe experience. J Endoluminal Endourol 2019;2:e20-9.

24. Chapman SJ, Grossman RC, FitzPatrick ME, Brady RR. Randomized controlled trial of plain English and visual abstracts for disseminating surgical research via social media. Br J Surg 2019:1611-6.

25. Shore R, Halsey J, Shah K, et al. Report of the AMA Council on Ethical and Judicial Affairs: Professionalism in the use of social media. J Clin Ethics 2011;22:165-72. 